\title{
A adoção internacional e a nacionalidade da criança adotada
}

\author{
Ângela Christina Boelhouwer Montagner ${ }^{1}$
}

\section{Resumo}

Este artigo tem como objeto de análise os efeitos da sentença constitutiva da adoção internacional, mormente a questão da nacionalidade da criança adotada. O que se identifica relevante nessa temática é a possibilidade da manutenção da nacionalidade brasileira e se a criança adquire a nacionalidade no país de acolhida, especialmente na Itália, vez que esse é o país que mais adota crianças brasileiras, revelando-se tema de grande importância para a garantia e defesa dos seus superiores interesses. Para tanto se busca identificar os pressupostos normativos da Convenção da Haia sobre adoção, verificando-se ao final que, no tocante aos efeitos da sentença constitutiva da adoção internacional, ambos os Estados Contratantes não estão cumprindo integralmente o regramento estabelecido na Convenção da Haia Relativa à Proteção das Crianças e à Cooperação em Matéria de Adoção Internacional, especialmente no que diz respeito ao reconhecimento da sentença estrangeira e à atribuição da nacionalidade, cujo efeito lhe é consectário.

Palavras-chave: Direito da Criança e do Adolescente. Adoção internacional. Nacionalidade.

\section{Introdução}

Tema polêmico e controvertido, a adoção internacional é hoje prática cada vez mais frequente, especialmente envolvendo crianças que vivem em países periféricos, as quais são acolhidas por pessoas residentes em países desenvolvidos, principalmente da Europa e dos Estados Unidos, na busca por concretizar o ideal da convivência familiar.

\footnotetext{
${ }^{1}$ Advogada, Professora do Centro Universitário de Brasília (UniCEUB) e do Centro Universitário do Distrito Federal (UDF), Especialista em Processo Civil pela Pontifícia Universidade Católica do Rio Grande do Sul (PUC/RS), Mestranda em Direito das Relações Internacionais pelo UniCEUB. angelamontagner@gmail.com
} 
Esse tipo de adoção caracteriza-se pela residência habitual de adotantes e adotados em países distintos, estando as partes subordinadas a diferentes soberanias e, por conseguinte, a diferentes sistemas jurídicos. Para aplacar as dificuldades daí decorrentes, foi adotada pela Conferência da Haia, em 1993, a Convenção Relativa à Proteção das Crianças e à Cooperação em Matéria de Adoção Internacional, a qual conseguiu em boa parte uniformizar os procedimentos específicos da adoção internacional.

No Brasil o tema está regulado pela Constituição Federal de 1988, pelo Estatuto da Criança e do Adolescente, de 1990, e pelo Decreto n ${ }^{\circ} 3.087$, de 1999, que promulgou a Convenção da Haia sobre adoção, ficando patente o pluralismo de fontes, mas evidenciando-se o diálogo entre todas. Dessa maneira, verifica-se que o Estatuto da Criança e do Adolescente está em harmonia com a Convenção da Haia no tocante às normas que regem a adoção internacional.

Quanto aos efeitos da sentença constitutiva da adoção internacional, o principal deles é, sem controvérsias, a criação do vínculo de parentesco com a família adotiva e o rompimento dos laços biológicos. Contudo, outro efeito se vislumbra: a atribuição da nacionalidade do país de acolhida para a criança adotada. Porém, por se tratar de matéria constitucional, não foi possível sua inserção expressa no texto da Convenção da Haia. Apesar disso, a compreensão da questão perpassa a própria Convenção, uma vez que prevê, em seu artigo 23-1, que a “adoção certificada em conformidade com a Convenção, pela autoridade competente do Estado onde ocorreu, será reconhecida de pleno direito pelos Estados Contratantes [...]”. Portanto, pode-se inferir a desnecessidade de um novo processo após a chegada da criança no país de acolhida, devendo a sentença ser acatada na sua totalidade.

Nesse contexto é que se estabelecem os objetivos do presente artigo: identificar se a Convenção da Haia sobre adoção vem sendo cumprida, especialmente no tocante aos efeitos da sentença de adoção internacional, e, principalmente, verificar como a questão da nacionalidade da criança adotada vem sendo tratada pelo Brasil e pela Itália, considerando-se que esse é o país que mais adota crianças brasileiras. 


\section{A convenção relativa à proteção das crianças e à cooperação em matéria de adoção internacional - Haia}

Em 1993, foi acordada, em Haia, a Convenção Relativa à Proteção e à Cooperação em Matéria de Adoção Internacional, conhecida como Convenção da Haia. Entende-se desde então, ser a adoção internacional medida excepcional, aplicada apenas de forma subsidiária, depois de esgotadas todas as possibilidades da criança viver em seu país de origem, no seio da sua família biológica ou numa família adotiva nacional.

Esse foi o primeiro instrumento a regular verdadeiramente a adoção internacional, ultrapassando as fronteiras regionais, denotando interesse mundial ${ }^{2}$. Seu principal objetivo foi estabelecer um sistema de cooperação administrativa e corresponsabilização entre os países de acolhida e de origem da criança. Isso se materializou pela imposição de uma série de obrigações entre os países envolvidos de maneira a assegurar prevalentemente os interesses do infante no processo de adoção como também o reconhecimento das adoções internacionais entre os países contratantes.

Naquele momento em que foi acordada a Convenção da Haia de 1993, fazia-se necessário um instrumento de cooperação internacional capaz de salvaguardar e garantir o cumprimento dos direitos das crianças levadas de seu país de origem por força da adoção internacional, cujo intento parece ter sido em boa parte alcançado.

Essa Convenção dispõe que as adoções internacionais serão controladas em cada país por uma Autoridade Central. No Brasil, ela é representada no âmbito federal pela Secretaria Especial de Direitos Humanos, de modo a implementar os objetivos traçados pela Convenção, colaborando com o oferecimento de informações sobre a legislação do país de residência do adotante e dando cumprimento aos ditames do instrumento internacional.

\footnotetext{
${ }^{2}$ Entretanto, Daniel Gutmann destaca que o campo de atuação desta Convenção ficou mitigado em razão da recusa dos países muçulmanos, desfavoráveis à adoção, em colaborar com a sua elaboração. Esses países não ratificaram a Convenção da Haia. GUTMANN, Daniel. Droit international privé. 3. ed. Paris: Dalloz, 2002. p. 167.
} 
A Convenção da Haia sobre adoção se revelou um importante e necessário instrumento para coibir situações duvidosas que se identificavam em relação às adoções internacionais, tais como subornos, falsificações de registros, coerção dos pais biológicos e lucros de "atravessadores", tudo isso aliado à ausência quase que total de regulamentação do assunto entre os países envolvidos. ${ }^{3}$

Regras como a obtenção do consentimento dos genitores, requisitos pessoais e efeitos da adoção foram regulados pela Convenção de 1993, impondo aos Estados- Partes a modernização das suas legislações internas para se adequarem às novas diretrizes, permitindo um tratamento paritário do instituto entre os países de origem e de acolhida, tendo em mira sempre o superior interesse da criança. ${ }^{4}$

A subsidiariedade da adoção internacional é clara no artigo $4^{\circ}$-b da Convenção, devendo tal medida ser adotada em caráter excepcional e somente após terem sido esgotadas todas as possibilidades de a criança permanecer primeiramente com sua família biológica ou, assim não sendo possível, em outro ambiente familiar em seu próprio país. O escopo do princípio da subsidiariedade é priorizar a permanência dos infantes no seu país de origem "sem privá-los, bruscamente, de conviver com seu idioma, suas tradições, cultura e acarretando o rompimento com suas raízes." 5

O estabelecimento de diretrizes para a averiguação da situação e das condições dos pretensos adotantes, mediante a expedição de certidão de habilitação, bem como a imposição da verificação de que o país de acolhida já autorizou ou irá autorizar a entrada e a residência permanente da criança em seu território são especificações que visam ao bem estar da criança e atendem aos seus superiores interesses.

Quanto aos efeitos da adoção internacional, o artigo 23 estabelece que, tendo transcorrido o processo de adoção nos termos da Convenção da Haia e

\footnotetext{
${ }^{3}$ FIGUEIRÊDO, Luiz Carlos de Barros. Adoção internacional: doutrina e prática. Curitiba: Juruá, 2006. p. 51.

${ }^{4}$ FIGUEIRÊDO, Luiz Carlos de Barros. Adoção internacional: doutrina e prática. Curitiba: Juruá, 2006. p. 53.

${ }^{5}$ PEREIRA, Tânia da Silva. Da adoção. In: DIAS, Maria Berenice; PEREIRA, Rodrigo da Cunha (Coord.). Direito de família e o novo Código Civil. 2. ed. Belo Horizonte: Del Rey, 2002. p. 150.
} 
sido homologado pela autoridade competente do país onde tramitou, a sentença constitutiva da adoção internacional deverá ser reconhecida de pleno direito pelos demais Estados Contratantes. Isso importa no reconhecimento da sentença estrangeira, para todos os efeitos, independentemente de homologação pelo poder judiciário do país de acolhida. ${ }^{6}$

Certo é que essa Convenção tem em mira a transparência dos processos de adoção, os quais deverão ser revestidos da mais expressa legalidade. Esses processos devem permitir que a criança saia de seu país para uma nova pátria, que deverá lhe receber como cidadão, e para o seio de uma nova família que a acolherá e lhe dará afeto, garantindo-lhe o direito fundamental da convivência familiar.

\section{A nacionalidade na adoção internacional}

A Declaração Universal dos Direitos Humanos proclamou a nacionalidade como um direito do ser humano. O Pacto Internacional dos Direitos Civis e Políticos, de 1966, reconheceu esse direito expressamente somente às crianças, nos termos do artigo $24, \$ 3 .^{7}$ Ademais, "considerando que a adoção visa à completa integração do adotado no seio da nova família”, é mister a concessão da nacionalidade pelo país de acolhida. ${ }^{8}$

Como se trata de matéria constitucional, não foi possível tratá-la expressamente no texto da Convenção da Haia sobre adoção. Contudo, para contornar esse impedimento material, foi estabelecido que as sentenças estrangeiras sobre adoção internacional tivessem homologação automática, produzindo imediatamente seus efeitos no país de acolhida da criança, sendo desnecessária a concessão de exequatur, incluindo-se aí a concessão da nacionalidade. Esse é o caso da Espanha, Noruega, Finlândia e Dinamarca, para citar alguns, mas não o é para a totalidade dos países contratantes, dentre os quais a Itália, justamente o país que mais adota no Brasil.

${ }^{6}$ NAZO, Georgette Nacarato. Adoção internacional: valor e importância das convenções internacionais vigentes no Brasil. São Paulo: O. Mendes, 1997. p. 19-20.

${ }^{7}$ Assim, no Pacto Internacional de 1966: Art. 24 [...] $\$ 3$. Toda criança terá o direito de adquirir uma nacionalidade.

${ }^{8}$ COSTA, Tarcísio José Martins. Adoção transnacional: um estudo sociojurídico e comparativo da legislação atual. Belo Horizonte: Del Rey, 1998. p. 157. 
Segundo Matthias Herdegen, "a nacionalidade serve de fundamento da estreita e especial relação de direitos e deveres entre o Estado e seus nacionais. Os nacionais, em sua totalidade, conformam uma associação de pessoas, a qual vem a constituir o Estado." Partindo-se dessa ideia de nacionalidade, a criança adotada e deslocada para outro país ficará à margem da sociedade, se não for detentora da nacionalidade desse Estado.

Por outro lado, Amilcar de Castro aduz que "nacionalidade é a permanente dependência de uma pessoa a determinado Estado." ${ }^{10}$ Ora, nesse sentido, mostrase essencial a atribuição da nacionalidade à criança submetida à adoção internacional, pois, de fato, após deixar o território brasileiro, ela ficará diretamente dependente da proteção do Estado de acolhida. Para o sucesso da adoção é necessária a adaptação da criança à nova família e a sua inserção na sociedade e na cultura do novo país. Ademais, é direito fundamental da criança ter reconhecida sua nacionalidade e, por consequência, conhecer sua identidade cultural, o que, segundo Erik Jayme, repercute nas regras concernentes à adoção internacional. ${ }^{11}$

Não são raros os posicionamentos que confundem nacionalidade com cidadania, aplicando-se de maneira equivocada os dois termos como sinônimos. Nesse sentido, Florisbal Del' Olmo estabelece que

Cidadania é, pois, o status jurídico de que se vêem investidos aqueles, dentre os nacionais, que, pelo implemento de condições especiais, como a idade, formam um vínculo político com o Estado, de que são exemplos os direitos-deveres de votar e ser votado. Embora empregada, algumas vezes, como sinônimo de nacionalidade, não deve com esta ser confundida, até porque a nacionalidade é mais abrangente, incluindo os menores e os incapazes, que não são abrangidos pelo instituto da cidadania, pelo menos na conotação jurídica que se está abordando. ${ }^{12}$ (grifo nosso).

${ }^{9}$ HERDEGEN, Matthias. Derecho internacional público. Tradução de Marcela Anzola. México, DF: Konrad Adenauer Stiftung, 2005. p. 193.

${ }^{10}$ CASTRO, Amilcar de. Direito internacional privado. 6. ed. Rio de Janeiro: Forense, 2005. p. 161.

${ }^{11}$ JAYME, Erik. Identité culturelle et integration: Le droit international privé postmoderne: cours general de droit international privé. In: RECUEIL des cours de l'académie de droit international de la Haye, 1995. Netherlands: Martinus Nijhoff, 1996. Tomo 251. p. 56.

${ }^{12}$ DEL 'OLMO, Florisbal de Souza. O MERCOSUL e a nacionalidade: estudo à luz do direito internacional. 1999. 188 f. Dissertação (Mestrado em Direito)- Universidade Regional Integrada Campus de Erechim, Erechim, 1999. 
Portanto, a nacionalidade decorre do vínculo que o indivíduo estabelece com o Estado pelo nascimento ou pelas vias derivadas, sendo a mais comum delas a naturalização, enquanto que a cidadania decorre do exercício dos direitos políticos e tem como pressuposto o reconhecimento da nacionalidade.

O fato é que se faz necessário o reconhecimento da nacionalidade, de modo especial para a criança adotada por estrangeiros. O reconhecimento da nacionalidade no país de acolhida está atrelado ao princípio do melhor interesse e à doutrina da proteção integral como um todo, para que a criança seja inserida na ordem de proteção do Estado para onde foi deslocada.

Nesse sentido, não sendo prontamente concedida a nacionalidade do país de acolhida, em extremada argumentação, poder-se-ia inferir que a criança adotada por meio da adoção internacional ficaria à mercê da própria sorte no estrangeiro, não tendo este país legitimidade nem interesse na defesa de seus direitos.

A atribuição da nacionalidade pelo país de acolhida à criança adotada perpassa pela identificação dos modos de aquisição da nacionalidade originária e secundária a serem fixados pelo direito constitucional de cada país.

Diz-se que a aquisição da nacionalidade é originária ou primária quando for atribuída pelo critério do jus sanguinis ou do jus soli. Para os países que acolhem o critério do jus soli, basta que alguém nasça em seu território para que seja considerado um nacional desse país. Nesse caso, por exemplo, se um casal de croatas residentes no Paraguai atravessarem a fronteira brasileira apenas porque julgam que determinado hospital de Foz do Iguaçu tem mais recursos, nascendo a criança nesta cidade, ela será brasileira nata, pois esse é o critério adotado pelo Brasil.

Pelo critério do jus sanguinis, a nacionalidade dos filhos é determinada pela nacionalidade dos pais, independentemente do local de nascimento daqueles. Esse critério é adotado por vários países europeus, inclusive pela Itália.

Diversamente, a nacionalidade adquirida ou secundária é identificada em um momento posterior ao nascimento, sendo exigida em alguns casos a expressa manifestação de vontade do indivíduo, como a que "transparece do pedido de naturalização". Ela também pode ser tácita, verificando-se "por força do imperativo editado pelo Estado", sem que haja oposição do indivíduo. No primeiro caso, 
a aquisição da nacionalidade se dá por solicitação; no segundo, por aceitação. ${ }^{13}$ Del'Olmo destaca ainda que a nacionalidade originária decorre de atribuição pelo Estado, enquanto que a nacionalidade secundária decorre de eleição pelo indivíduo. $^{14}$

Em relação à adoção internacional, há duas situações relacionadas à nacionalidade que precisam ser identificadas. A primeira, se há manutenção da nacionalidade do país de origem, no caso a brasileira; a segunda, se há aquisição da nacionalidade do país de acolhida e, de modo especial, como esse assunto é tratado na Itália por ser o país que mais adota no Brasil.

Segundo Van Loon, poucos países regulam expressamente a perda da nacionalidade em decorrência de adoção feita por estrangeiro, como a Coreia por exemplo. Por outro lado, boa parte das legislações dos Estados trata explicitamente da aquisição da nacionalidade, como a Espanha. Em outros sistemas, a lei é omissa, como Israel, Áustria e o próprio Brasil. Nos casos de omissão legal, o autor entende que a adoção internacional não produz o efeito de atribuir a nacionalidade, o que, data vênia, precisa ser analisado sistematicamente, de acordo com o ordenamento jurídico de cada país. $^{15}$

Destarte, a tendência na maioria das legislações é de atribuir pelo menos alguns efeitos que podem ser identificados desde a facilitação do processo de naturalização (como acontece nos Estados Unidos, em decorrência da Lei Clinton), até pela aquisição opcional da nacionalidade, como na França (no caso de ser uma adoção simples). A aquisição automática propriamente dita, identificada na maioria dos países europeus e africanos, é rara nos países asiáticos e no continente americano. ${ }^{16}$

${ }^{13}$ FERREIRA FILHO, Manoel Gonçalves. Curso de direito constitucional. 21. ed. São Paulo: Saraiva, 1994. p. 96.

${ }^{14}$ DEL 'OLMO, Florisbal de Souza. O MERCOSUL e a nacionalidade: estudo à luz do direito internacional. 1999. 188 f. Dissertação (Mestrado em Direito)- Universidade Regional Integrada Campus de Erechim, Erechim, 1999.

${ }^{15}$ VAN LOON, J. H. A. International co-operation and protection of children with regard to intercountry adoption. In: RECUEIL des cours de l'académie de droit international de la Haye, 1993. Netherlands: Martinus Nijhoff, 1994. Tomo 244. p. 298.

${ }^{16}$ VAN LOON, J. H. A. International co-operation and protection of children with regard to intercountry adoption. In: RECUEIL des cours de l'académie de droit international de la Haye, 1993. Netherlands: Martinus Nijhoff, 1994. Tomo 244. p. 299. 


\section{A nacionalidade brasileira após a sentença constitutiva da adoção internacional}

O Brasil estabeleceu, no artigo 12, $\$ 4^{\circ}$ da Constituição Federal de 1988, que há perda da nacionalidade brasileira quando um brasileiro nato adquire outra nacionalidade. Excetuam-se apenas os casos em que essa aquisição se dê pela via originária no país estrangeiro ou imposição de naturalização pela lei estrangeira ao brasileiro residente no exterior, para o exercício de direitos civis ou como condição de sua permanência no país.

Para Luiz Carlos Figueirêdo, se a adoção internacional foi realizada por adotantes estrangeiros, importa em perda da nacionalidade brasileira para a criança adotada, por força do artigo $12, \$ 4^{\circ}$, inciso II da Constituição Federal de 1988, em interpretação conjunta com o artigo 26 da Convenção da Haia de 1993, ressalvada a hipótese em "que os adotantes, ou um deles, domiciliados no exterior, seja $(\mathrm{m})$ brasileiro(s)" ou a opção de nacionalidade posterior. ${ }^{17}{ }^{18}$ Entretanto, cumpre ressaltar que a Convenção da Haia não enfrenta a questão da nacionalidade, conforme anteriormente mencionado, não podendo, por conseguinte, servir de argumento para sua perda em relação ao país de origem.

Também Valdir Sznick acolhe esse entendimento, sem, contudo, apresentar qualquer fundamentação, afirmando apenas que o adotado deverá receber a nacionalidade do país de acolhida. ${ }^{19}$

Não obstante o posicionamento dos autores, é importante considerar que a própria Constituição Federal de 1988 estabeleceu no artigo 227 a igualdade jurídica entre todos os filhos, sem qualquer discriminação quanto à origem da filiação. Esse dispositivo trata de direitos fundamentais de proteção à família. Nesse sentido, seria discriminatória a perda da nacionalidade brasileira, considerando o critério do jus soli, pelo simples fato de a criança

${ }^{17}$ FIGUEIRÊDO, Luiz Carlos de Barros. Adoção internacional: doutrina e prática. Curitiba: Juruá, 2006. p. 72.

${ }^{18}$ Jacob Dolinger, em nota de rodapé, ataca veementemente o posicionamento de Luiz Carlos Figueirêdo e demonstra que não há qualquer justificativa identificada no texto constitucional que confirme a perda da nacionalidade em razão da aquisição de outra decorrente da adoção internacional. DOLINGER, Jacob. Direito internacional privado: a criança no direito internacional. Rio de Janeiro: Renovar, 2003. p. 425-426.

${ }^{19}$ SZNICK, Valdir. Adoção. 3. ed. rev. e atual. São Paulo: Universitária de Direito, 1999. p. 468. 
ter se tornado filha de estrangeiros em decorrência da adoção internacional. Ademais, segundo Bernardo Pimentel,

Se o brasileiro adquiriu outra nacionalidade em virtude do reconhecimento oficial da nacionalidade primária pela legislação de outro Estado, subsiste a nacionalidade brasileira, razão pela qual a pessoa passa a ser polipátrid,, em virtude da permissão contida na alínea $a$ do inciso II. [...] Em suma, justificada a necessidade da aquisição da nacionalidade estrangeira pelo brasileiro residente no exterior, subsiste a nacionalidade brasileira. ${ }^{20}$

Portanto, se a aquisição da nacionalidade é derivada da sentença constitutiva da adoção, trata-se de aquisição involuntária ou por atribuição, como leciona Del'Olmo, mesmo quando os pais adotivos precisam formalizar essa situação junto aos órgãos de controle da imigração, no momento da chegada da criança ao país, assim como nos casos em que a lei do país de acolhida expressamente prevê a concessão da nacionalidade, estando tais situações subsumidas na alínea a), do inciso II do artigo 12 da Carta Magna de 1988.

Nesse sentido, Del'Olmo afirma que “a criança posta em adoção jamais perde, por esse ato, a nacionalidade decorrente do fato de haver nascido no Brasil", vez que o novo registro civil decorrente da adoção altera apenas os nomes dos pais e dos avós, quiçá o da criança, mas em nada modifica o local e a data do nascimento. ${ }^{21}$ Logo, uma criança nascida no Brasil será sempre brasileira pelo critério do jus soli.

Em relação à aquisição da nacionalidade em razão da adoção internacional, também não é possível falar em eleição por parte do adotado, pois a esse não é dado o poder de escolha, até porque ele é juridicamente incapaz, não se enquadrando assim entre as formas de aquisição secundária da nacionalidade que poderiam afastar a brasileira, sendo decorrência apenas da sentença constitutiva da adoção internacional, tenha essa efeito automático ou não.

Também não se revela como opção mais adequada falar em naturalização da criança no país de acolhida. O máximo que se poderia admitir, tomando por

\footnotetext{
${ }^{20}$ SOUZA, Bernardo Pimentel. Compêndio de direito constitucional. Brasília: Brasília Jurídica, 2006. p. 37.

${ }^{21}$ DEL 'OLMO, Florisbal de Souza. O MERCOSUL e a nacionalidade: estudo à luz do direito internacional. 1999. 188 f. Dissertação (Mestrado em Direito)- Universidade Regional Integrada Campus de Erechim, Erechim, 1999.
} 
analogia uma norma da primeira Constituição da República ${ }^{22}$, é a sua nacionalização, que significa “a determinação da nacionalidade de um indivíduo pelas condições de seu nascimento e filiação, e não pela expressão de sua vontade em adaptar uma nacionalidade," ${ }^{23}$ ou seja, a aquisição de outra nacionalidade por imperativo legal e não por ato de vontade. Nos termos do artigo $12, \$ 4^{\circ}, \mathrm{II}$, a) da Constituição Federal de 1988, esse fato não conduz à perda da nacionalidade brasileira.

De outro norte, o Brasil anda na contramão de seu próprio entendimento, quando se trata de criança estrangeira adotada por brasileiro. ${ }^{24}$ Em primeiro lugar, porque não reconhece automaticamente a sentença constitutiva de adoção proferida por tribunal estrangeiro, impondo a concessão de exequatur ${ }^{25}$ pela via da homologação de sentença estrangeira. Em segundo lugar, porque não reconhece a criança estrangeira adotada como brasileira nata, na medida em que não lhe concede a nacionalidade, sendo necessário pedido de naturalização.

O fundamento para tanto é que a impossibilidade de concessão de nacionalidade decorre do próprio texto constitucional que vincula o Brasil ao critério do jus soli ou, excepcionalmente, ao critério do jus sanguinis, nos casos de filhos de brasileiros nascidos no exterior.

${ }^{22}$ A Constituição brasileira de 1891 previa em seu artigo 69, 4º $)$ que todos os estrangeiros residentes no Brasil em 15 de novembro de 1889 seriam considerados brasileiros, se não protestassem por sua própria nacionalidade no prazo de seis meses, a contar da entrada em vigor da Constituição da República.

${ }^{23}$ CAMPOS FILHO, Paulo Barbosa de. "Pontos" de direito internacional privado. São Paulo: Livraria Acadêmica, 1924. p. 71.

${ }^{24}$ Não foi possível comprovar o número de adoções dessa natureza, mas sabe-se que são poucos os casos segundo informação da ACAF.

${ }^{25}$ Nesse sentido, já decidiu o Supremo Tribunal Federal: Sentença Estrangeira; é de ser homologada, em face do disposto no art. 101, i, alínea 'g' da vigente Constituição, ainda que meramente declaratória do estado das pessoas, a fim de se tornarem exeqüíveis no Brasil. Trata-se, no caso, de uma decisão da corte de apelação de Florença, decretoria [sic] de adoção (Código Civil italiano, arts. 312/313); configura-se, pois, uma sentença constitutiva, que escapa a exceção do parágrafo único do art. 15 da Lei de Introdução do Código Civil brasileiro. Recebimento de embargos [grifou-se]. BRASIL. Supremo Tribunal Federal. Sentença Estrangeira n. 1297 (Itália). Embargantes: Gofredo Griselli e Fé Franch Griselli. Relator: Min. Ribeiro da Costa. Rio de Janeiro, 24 de maio de 1955. Disponível em: <http://www.stf.jus.br/portal/jurisprudencia/ listarJurisprudencia.asp?s1=(1297.NUME.OU1297.ACMS.) (adoçãosentença.EMEN.OUadoçãosentença. IND.)\&base $=$ baseAcordaos $>$ Acesso em: 30 maio 2009. 
Esse entendimento é corroborado por Miguel Jerônymo Ferrante o qual diz que "filho adotivo de brasileiros, nascido no estrangeiro, não pode optar pela nacionalidade brasileira. É estrangeiro e, como tal, só poderá adquirir a nacionalidade brasileira por via de naturalização" ${ }^{26}$. Seu pensamento está estribado no fato de o Brasil ter ratificado a Convenção da Haia de 1930, conhecida como Convenção Concernente a Certas Questões Relativas aos Conflitos de Leis sobre a Nacionalidade, tendo sido imposta reserva justamente ao artigo 17, que diz:

Se a lei de um Estado admitir a perda da nacionalidade, em consequência da adoção, esta perda ficará, entretanto, subordinada à aquisição pelo adotado da nacionalidade do adotante, de acordo com a lei do Estado, de que este for nacional, relativa aos efeitos da adoção sobre a nacionalidade. ${ }^{27}$

Também Francisco Guimarães afirma que “a adoção de estrangeiro por brasileiro não produz efeitos sobre a nacionalidade"28.

Nesse sentido, seria necessário entender que, como a criança estrangeira adotada, por óbvio, não nasceu no Brasil, a ela não é possível a aplicação do critério do jus soli. Por não ser filha "legítima” de brasileiros, não é possível aplicar o critério do jus sanguinis. Contudo, novamente entendendo-se que a adoção estabelece vínculo de filiação e que a própria Constituição Federal de 1988 proíbe qualquer designação discriminatória entre filhos, independente de sua origem, seja natural ou civil, não há porque dar tratamento diferenciado aos filhos adotados, sob pena de impor uma discriminação vedada pelo próprio texto constitucional no artigo 227, $\$ 6^{\circ}$ : “os filhos, havidos ou não da relação de casamento, ou por adoção, terão os mesmos direitos e qualificações, proibidas quaisquer designações discriminatórias relativas à filiação". Se os filhos de brasileiros que nascem no exterior são brasileiros natos, os filhos adotados em outro país também deverão ser.

${ }^{26}$ FERRANTE, Miguel Jerônymo. Nacionalidade: brasileiros natos e naturalizados. 2. ed. São Paulo: Saraiva, 1984. p. 51.

${ }^{27}$ BRASIL. Decreto n. 21.798 de 6 de setembro de 1932. Promulga a convenção concernente a certas questões relativas aos conflitos de leis sobre a nacionalidade e três protocolos sobre nacionalidade firmados na Haia, a 12 de abril de 1930. Brasília, 1932. Disponível em: <http://www2.mre.gov.br/dai/conflito.htm>. Acesso em: 27 maio 2009.

${ }^{28}$ GUIMARÃES, Francisco Xavier da Silva Guimarães. Nacionalidade: aquisição, perda e reaquisição. Rio de Janeiro: Forense, 1995. p. 15. 


\section{A nacionalidade da criança adotada no país de acolhida: o caso da Itália}

A importância da nacionalidade tem sua justificativa no próprio sistema legal da maioria dos países, em termos de benefícios e garantias. Portanto, deixar de conceder à criança estrangeira adotada o direito de adquirir a nacionalidade iria contradizer a própria ideia de adoção ${ }^{29}$, sendo essa uma das maiores preocupações da Autoridade Central Administrativa Federal (ACAF), no que diz respeito ao período pós-adotivo.

Além disso, a Declaração das Nações Unidas sobre os Princípios Sociais e Legais Relativos ao Bem Estar das Crianças, de 1986, no que tange às adoções internacionais, recomenda expressamente que deverá ser "garantido que a criança poderá migrar para se juntar aos pais adotivos e poderá obter a nacionalidade deles" ${ }^{30}$..No mesmo sentido, manifestou-se o Instituto de Direito Internacional, na sessão de Roma, em 1973:

Considerando que a diferença de nacionalidade entre adotado e adotantes pode comprometer a unidade no seio da família adotiva, recomenda que as autoridades competentes em cada Estado estabeleçam regras, procedimentos e práticas que permitam atribuir ao adotado menor, em curto prazo, a nacionalidade dos adotantes $^{31}$.

A escolha da Itália para identificar o tratamento dado à presente questão se justifica por ser o principal país de acolhida de crianças brasileiras, muito à frente de todos os demais países que realizam adoções internacionais no Brasil. Esse dado foi obtido por meio de questionamento feito por correio eletrônico, respondido por 12 Comissões Estaduais Judiciárias de Adoções Internacionais (CEJAI'S), muito embora as 27 Autoridades Centrais estaduais tenham sido contatadas. Ainda que menos da metade das CEJAI'S tenha se interessado em

${ }^{29}$ VAN LOON, J. H. A. International co-operation and protection of children with regard to intercountry adoption. In: RECUEIL des cours de l'académie de droit international de la Haye, 1993. Netherlands: Martinus Nijhoff, 1994. Tomo 244. p. 298-299.

${ }^{30}$ DOLINGER, Jacob. Direito internacional privado: a criança no direito internacional. Rio de Janeiro: Renovar, 2003. p. 425.

${ }^{31}$ Revue Critique, 1974, p. 181 apud JATAHY, Vera Maria Barreira. A adoção internacional: o direito comparado e as normas estatutárias. In: Estatuto da Criança e do Adolescente: estudos sócio jurídicos. Rio de Janeiro: Renovar, 1992. p. 198. 
responder à pesquisa, esse dado também foi confirmado pelo Delegado Chefe da Divisão de Passaportes da Polícia Federal ${ }^{32}$.

No período de janeiro de 2008 a março de 2009, foram realizadas no Brasil 331 adoções só para a Itália, contra 24 para a França, que figura em segundo lugar. Além desses países, foi possível identificar a realização de 15 adoções para a Espanha, 15 para os Estados Unidos, 10 para a Noruega, 3 para a Alemanha, 1 para o Canadá, 1 para a Suíça e 1 para Portugal ${ }^{33}$.

Na Itália, as adoções nacionais e internacionais estão reguladas pela Legge n. 184/83, com as modificações introduzidas pela Legge n. 476/98 especificamente quanto às últimas.

Especialmente em relação às adoções internacionais, a Itália não reconhece automaticamente a sentença constitutiva da adoção internacional, impondo sua revisão pelo Tribunale per i Minorenni, com competência na região de residência dos adotantes, o qual irá conceder a "declaração de eficácia” do provimento de adoção emanado de autoridade estrangeira, fazendo surgir na prática o fenômeno da dupla adoção ${ }^{34}$. Por consequência, a nacionalidade somente é concedida após o trânsito em julgado dessa declaração de eficácia. Assim, obtendo-se tal declaração, a nacionalidade italiana é concedida, nos termos da Legge n. 184/83, artigo 39: “o menor de nacionalidade estrangeira adotado por casais de cidadania italiana adquire o direito a tal cidadania"35.

Com efeito, o que na prática se identifica é que a Itália não se limita a fazer uma verificação formal da sentença de adoção, mas adentra no seu mérito, podendo lhe dar ou não validade, sob a alegação de que a vontade do legislador, ao

\footnotetext{
${ }^{32}$ DUARTE, Rodrigo Guimarães. A expedição de passaporte após a sentença de adoção internacional. Brasília: Departamento de Polícia Federal, 2009. Entrevista concedida a Ângela Christina Boelhouwer Montagner.

${ }^{33}$ Segundo dados fornecidos pelas CEJAI'S do CE, RN, BA, GO, MG, SP e SC. As CEJAI'S de RR, AP, AL, DF e RS informaram que nenhuma adoção internacional foi realizada no período pesquisado.

${ }^{34}$ JATAHY, Vera Maria Barreira. A adoção internacional: o direito comparado e as normas estatutárias. In: Estatuto da Criança e do Adolescente: estudos sócio jurídicos. Rio de Janeiro: Renovar, 1992. p. 195.

${ }^{35}$ ITÁLIA. Legge n. 184, de 4 de maio de 1983. Diritto del minore ad una famiglia. Roma, 1983. Disponível em: <http://www.giustizia.it/cassazione/ leggi/l184_83.html>. Acesso em: 5 jan. 2009.
} 
introduzir o artigo 35 na Legge n. $476 / 98^{36}$, era atribuir tais poderes ao magistrado. Dessa maneira, o legislador não limitou o Tribunal de Menores a apenas verificar se a sentença de adoção prolatada no país de origem está conforme a Convenção da Haia e assim determinar a transcrição do provimento estrangeiro perante o registro civil. Esse Tribunal também pode verificar se a sentença está de acordo com os princípios fundamentais do direito de família e dos menores italiano, buscando-se identificar, inclusive, a adaptação da criança estrangeira à família italiana como condição para a transcrição da sentença estrangeira.

Nesse sentido, Giovanni Manera aduz que a atividade precípua do Tribunal de Menores é verificar se a sentença estrangeira de adoção está ou não conforme os princípios fundamentais do direito italiano e da Convenção da Haia, sendo apenas secundária a ordem de transcrição, ou sua recusa, perante o registro civil para a aquisição da nacionalidade. Isto é, a criança estrangeira adotada em decorrência de um provimento de adoção declarado contrário aos princípios fundamentais não se torna nem filho adotivo dos adotantes, nem cidadão italiano ${ }^{37}$.

Segundo o mesmo autor, como o legislador italiano promulgou a Legge n. 476 após a ratificação da Convenção da Haia, não se limitando apenas a recepcionar a Convenção, mas estabelecendo disposições específicas no tocante ao instituto da adoção internacional, o artigo 35 da referida lei acabou por integrar e ao mesmo tempo modificar a norma convencional, estabelecendo "disposizioni di attuazione e integrazione della Convenzione, que a volte divergono sensibilmente dalla disciplina convenzionale". Assim sendo, havendo divergência entre o que dispõe a Convenção e a Legge n. 476, esta terá prevalência, por entender que a Convenção é norma de caráter geral e que a Legge n. 476 é norma especial ${ }^{38}$.

${ }^{36}$ ITÁLIA. Legge n. 476, de 31 de dezembro de 1998. Ratifica ed esecuzione della Convenzione per la tutela dei minori e la cooperazione in materia di adozione internazionale, fatta a L'Aja il 29 maggio 1993. Modifiche alla legge 4 maggio 1983, n. 184, in tema di adozione di minori stranieri. Roma, 1998. Disponível em: <http://www.camera.it/parlam/ leggi/98476l.htm>. Acesso em: 05 jan. 2009.

${ }^{37}$ MANERA, Giovanni. Osservazioni su alcuni punti più qualificanti della nuova disciplina dell'adozione Internazionale dei minori. Giustizia civile: rivista mensile di giurisprudenza, [S.1.], v. 56, n. 6, p. 277-297, jun. 2006.

${ }^{38}$ MANERA, Giovanni. Osservazioni su alcuni punti più qualificanti della nuova disciplina dell'adozione Internazionale dei minori. Giustizia civile: rivista mensile di giurisprudenza, [S.1.], v. 56, n. 6, p. 277-297, jun. 2006. 
O que se depreende, portanto, é que na Itália uma sentença estrangeira de adoção, ainda que proveniente de um Estado- Parte da Convenção da Haia, mormente do Brasil que foi um dos primeiros países contratantes a adequar sua legislação de proteção à infância, não tem o efeito direto estabelecido na Convenção, sem a manifestação expressa do Tribunal de Menores. Desse modo, pode-se chegar ao absurdo de haver uma sentença de adoção válida no Brasil e não reconhecida na Itália, embora ambos os países sejam Partes da Convenção da Haia. Como, nos termos da legislação brasileira, o ato jurídico está perfeito e acabado após o trânsito em julgado da sentença, a criança brasileira é, ato contínuo, deslocada para a Itália na companhia de seus pais adotivos, mas ainda corre o risco de não ter a adoção reconhecida neste país e de não receber a nacionalidade no país que 'deveria ser' de acolhida.

Com efeito, essas exigências não se justificam nos casos em que a sentença de adoção foi proferida em países contratantes, nos quais obrigatoriamente a adoção foi concluída por meio de processo judicial. Ainda que a Itália receba crianças adotadas em outros países não partes ${ }^{39}$ (o Vietnã, por exemplo), os quais por vezes permitem que a adoção internacional seja feita por escritura pública (o que justificaria o interesse do Estado italiano em revisar a adoção), o mesmo tratamento não pode ser dispensado às adoções originadas em Estados Contratantes como o Brasil.

Não se desconhece por certo que a mudança de procedimento na Itália exige uma alteração legislativa, o que demanda tempo; contudo, no caso brasileiro, parece urgente a necessidade da realização de um acordo bilateral para solucionar essa problemática, de modo que a Itália cumpra verdadeiramente o que dispõe a Convenção da Haia, no sentido de dar eficácia automática aos provimentos judiciais brasileiros de adoção internacional.

\footnotetext{
${ }^{39}$ Em 2008, 53,6\% das crianças estrangeiras adotadas por italianos foram provenientes de países não contratantes como a Rússia, Ucrânia, Etiópia e Vietnã, por exemplo. DATI e prospettive nelle adozioni internazionali. Firenze, 2008. Disponível em: <http://new.commissioneadozioni.it/media/48288/dati\&prosp\% 202_2008.pdf>. Acesso em: 01 jun. 2009.
} 


\section{Conclusão}

Não se olvida que "as múltiplas nacionalidades são indesejáveis, porque podem implicar a existência de direitos e deveres que se contrapõem entre si" ${ }^{40}$, mas, nos casos de adoção internacional, essa ainda é a melhor solução em face do princípio do melhor interesse da criança adotada. $\mathrm{O}$ fato de não ser um nacional do país acaba por deixar a criança em situação de maior vulnerabilidade, o que não se coaduna com a Doutrina da Proteção Integral.

A Convenção da Haia sobre adoção, em linhas gerais, estabeleceu um sistema de cooperação administrativa entre os países de origem e de acolhida, de modo a assegurar os superiores interesses da criança no processo de adoção internacional, como também o reconhecimento de pleno direito das adoções internacionais, quando realizadas entre países contratantes. Dentre outras disposições, a Convenção da Haia determinou a criação de Autoridades Centrais em cada Estado-Parte para implementar as disposições da Convenção e dar cumprimento aos seus ditames. Outras regras foram estabelecidas, tais como a necessidade de obtenção do consentimento dos genitores, requisitos pessoais e efeitos da adoção, a efetivação da adoção internacional apenas em caráter subsidiário, bem como a fixação de diretrizes para a averiguação dos pretensos adotantes, mediante prévio processo de habilitação e a confirmação da autorização pelo país de acolhida, no que se refere à imigração da criança adotada.

Para a implementação dos ditames da Convenção da Haia sobre adoção foi necessária a adequação das legislações dos Estados-Partes, no que diz respeito à adoção internacional. No caso brasileiro, o Estatuto da Criança e do Adolescente, promulgado em 1990, já trazia em seu bojo os princípios da Convenção da Haia, uma vez que o Brasil acompanhou todas as discussões da Convenção como membro ad hoc.

Como Contratante da Convenção Relativa à Proteção das Crianças e à Cooperação em Matéria de Adoção Internacional, foi possível identificar que o Brasil, em termos legislativos, cumpriu com todas as suas obrigações

${ }^{40}$ HERDEGEN, Matthias. Derecho internacional público. Tradução de Marcela Anzola. México, DF: Konrad Adenauer Stiftung, 2005. p. 196. 
de Estado-Parte, visto que o Estatuto da Criança e do Adolescente e a própria Constituição Federal de 1988 estão em absoluta consonância com os pressupostos da aludida Convenção.

No tocante à nacionalidade da criança em face da adoção internacional, identificam-se alguns percalços. Duas observações precisam ser feitas: primeiro, que o direito à nacionalidade é um direito fundamental que permite ao indivíduo o pleno exercício da cidadania; segundo, que a Convenção da Haia estabelece que a sentença estrangeira constitutiva da adoção internacional deve ser reconhecida de pleno direito pelo Estado de acolhida.

Com relação à nacionalidade brasileira, ela é mantida diante da aquisição da nacionalidade dos pais adotivos, já que a nacionalidade do país de acolhida é atribuída por esse Estado e não solicitada pela criança, tratando-se verdadeiramente de aquisição originária de nacionalidade.

Quanto à aquisição da nacionalidade no país de acolhida, embora não fosse o escopo inicial do trabalho, foi possível identificar como o Brasil procede nos casos em que brasileiros adotam crianças estrangeiras. Verificou-se que o Brasil não reconhece de pleno direito as sentenças de adoção internacional proferidas em outros Estados, impondo a realização do processo judicial de homologação da sentença estrangeira e do processo administrativo de naturalização. Portanto, além de descumprir a Convenção da Haia, afronta a própria Constituição Federal de 1988, estabelecendo discriminação em relação à filiação adotiva, na medida em que os filhos de brasileiros nascidos no exterior são brasileiros natos, e os adotados podem ser apenas naturalizados.

No caso de crianças brasileiras adotadas por estrangeiros, verificou-se como se procede na Itália, recorte feito a partir da constatação de que $82,54 \%$ das adoções internacionais realizadas no Brasil, no período de janeiro de 2008 a março de 2009, foram para aquele país. A Itália tem um complexo mecanismo de reconhecimento da sentença estrangeira de adoção, descumprindo o disposto na Convenção da Haia, quanto ao reconhecimento de pleno direito da sentença de adoção internacional. Nesse país, chega-se ao absurdo de não se reconhecer uma adoção realizada em um Estado-Parte (inclusive oriunda do Brasil), o que efetivamente viola a Convenção da Haia. 
A problemática toma vulto diante da constatação de que a Itália é o país que mais adota crianças brasileiras, deixando-as vulneráveis. Impõe-se um questionamento quanto à observância do princípio do melhor interesse. Não se está aqui fazendo qualquer apologia contra as adoções internacionais para a Itália, mesmo porque, até o momento, todas as situações de risco foram acompanhadas diretamente pelas respectivas Autoridades Centrais. Contudo, é imperativo o encontro de uma solução para essa problemática, seja pela mudança da lei italiana (talvez o caminho mais difícil), seja pela formalização de um acordo bilateral entre os dois países que garanta na Itália o cumprimento da Convenção da Haia, no que diz respeito ao reconhecimento da eficácia automática dos provimentos judiciais brasileiros de adoção internacional. Como solução mais drástica, pode-se determinar que as crianças brasileiras adotadas por casais residentes na Itália somente saiam do Brasil após a "declaração de eficácia" ter sido proferida pelo competente tribunal italiano, postergando os efeitos do trânsito em julgado da sentença brasileira no próprio Brasil.

\section{The international adoption and the nationality of the adopted child}

\section{Abstract}

This article has as object the analysis of the effects of the constituent sentence in intercountry adoption, including the nationality of the adopted child. The most relevant issues identified in this study are the possibility of the maintenance of the Brazilian nationality, and if the child acquires the nationality of the host country, especially Italy, country that most adopts Brazilian children; matter of great importance for the security and defense of their best interests. Thus, this study tried to identify the normative assumptions of the Hague Convention on adoption, concluding that with regard to the effects of the constituent sentence of intercountry adoption, both countries are not fully complying with the rules established in the Hague Convention on Protection of Children and Co-operation in Respect of Intercountry Adoption, especially in regards of the recognition of a foreign ruling. In regards to nationality, it founds that the Brazilian nationality is maintained and in the case of Italy, that the possibility of its allocation is linked to the declaration of effectiveness given by the Tribunale per i Minorenni.

Keywords: Child and Adolescent Law. Intercountry adoption. Nationality 


\section{Referências}

BRASIL. Decreto n. 21.798 de 6 de setembro de 1932. Promulga a convenção concernente a certas questões relativas aos conflitos de leis sobre a nacionalidade e três protocolos sobre nacionalidade firmados na Haia, a 12 de abril de 1930. Brasília, 1932. Disponível em: <http://www2.mre.gov.br/dai/conflito.htm>. Acesso em: 27 maio 2009.

BRASIL. Supremo Tribunal Federal. Sentença Estrangeira n. 1297 (Itália). Embargantes: Gofredo Griselli e Fé Franch Griselli. Relator: Min. Ribeiro da Costa. Rio de Janeiro, 24 de maio de 1955. Disponível em: <http://www.stf.jus.br/portal/ jurisprudencia/listarJurisprudencia.asp?s1=(1297.NUME. OU1297.ACMS.) (adoção sentença.EMEN.OU adoção sentença.IND.)\&base=baseAcordaos> Acesso em: 30 maio 2009.

CAMPOS FILHO, Paulo Barbosa de. "Pontos" de direito internacional privado. São Paulo: Livraria Acadêmica, 1924.

CASTRO, Amilcar de. Direito internacional privado. 6. ed. Rio de Janeiro: Forense, 2005.

COSTA, Tarcísio José Martins. Adoção transnacional: um estudo sociojurídico e comparativo da legislação atual. Belo Horizonte: Del Rey, 1998.

DATI e prospettive nelle adozioni internazionali. Firenze, 2008. Disponível em: $<$ http://new.commissioneadozioni.it/media/48288/dati\&prosp\%202_ 2008.pdf >. Acesso em: 01 jun. 2009.

DEL'OLMO, Florisbal de Souza. O MERCOSUL e a nacionalidade: estudo à luz do direito internacional. 1999. 188 f. Dissertação (Mestrado em Direito)- Universidade Regional Integrada Campus de Erechim, Erechim, 1999.

DOLINGER, Jacob. Direito internacional privado: a criança no direito internacional. Rio de Janeiro: Renovar, 2003.

DUARTE, Rodrigo Guimarães. A expedição de passaporte após a sentença de adoção internacional. Brasília: Departamento de Polícia Federal, 2009. Entrevista concedida a Ângela Christina Boelhouwer Montagner.

FERRANTE, Miguel Jerônymo. Nacionalidade: brasileiros natos e naturalizados. 2. ed. São Paulo: Saraiva, 1984.

FERREIRA FILHO, Manoel Gonçalves. Curso de direito constitucional. 21. ed. São Paulo: Saraiva, 1994. 
FIGUEIRÊDO, Luiz Carlos de Barros. Adoção internacional: doutrina e prática. Curitiba: Juruá, 2006.

GUIMARÃES, Francisco Xavier da Silva Guimarães. Nacionalidade: aquisição, perda e reaquisição. Rio de Janeiro: Forense, 1995.

GUTMANN, Daniel. Droit international privé. 3. ed. Paris: Dalloz, 2002.

HERDEGEN, Matthias. Derecho internacional público. Tradução de Marcela Anzola. México, DF: Konrad Adenauer Stiftung, 2005.

ITÁLIA. Legge n. 184, de 4 de maio de 1983. Diritto del minore ad una famiglia. Roma, 1983. Disponível em: <http://www.giustizia.it/cassazione/ leggi/1184_83. html>. Acesso em: 5 jan. 2009.

ITÁLIA. Legge n. 476, de 31 de dezembro de 1998. Ratifica ed esecuzione della Convenzione per la tutela dei minori e la cooperazione in materia di adozione internazionale, fatta a L'Aja il 29 maggio 1993. Modifiche alla legge 4 maggio 1983, n. 184, in tema di adozione di minori stranieri. Roma, 1998. Disponível em: <http:// www.camera.it/parlam/leggi/98476l.htm>. Acesso em: 05 jan. 2009.

JATAHY, Vera Maria Barreira. A adoção internacional: o direito comparado e as normas estatutárias. In: - Estatuto da Criança e do Adolescente: estudos sócio jurídicos. Rio de Janeiro: Renovar, 1992.

JAYME, Erik. Identité culturelle et integration: Le droit international privé postmoderne: cours general de droit international privé. In: RECUEIL des cours de l'académie de droit international de la Haye, 1995. Netherlands: Martinus Nijhoff, 1996. Tomo 251.

MANERA, Giovanni. Osservazioni su alcuni punti più qualificanti della nuova disciplina dell' adozione Internazionale dei minori. Giustizia civile: rivista mensile di giurisprudenza, [S.1.], v. 56, n. 6, p. 277-297, jun. 2006.

NAZO, Georgette Nacarato. Adoção internacional: valor e importância das convenções internacionais vigentes no Brasil. São Paulo: O. Mendes, 1997.

PEREIRA, Tânia da Silva. Da adoção. In: DIAS, Maria Berenice; PEREIRA, Rodrigo da Cunha (Coord.). Direito de família e o novo Código Civil. 2. ed. Belo Horizonte: Del Rey, 2002. 

Prismas: Dir., Pol. Publ. e Mundial., Brasília, v. 6, n. 2, p. 399-420, jul./dez. 2009
Ângela Christina Boelhouwer Montagner

SOUZA, Bernardo Pimentel. Compêndio de direito constitucional. Brasília: Brasília Jurídica, 2006.

SZNICK, Valdir. Adoção. 3. ed. rev. e atual. São Paulo: Universitária de Direito, 1999.

VAN LOON, J. H. A. International co-operation and protection of children with regard to intercountry adoption. In: RECUEIL des cours de l'académie de droit international de la Haye, 1993. Netherlands: Martinus Nijhoff, 1994. Tomo 244. 